\title{
SOX4 expression is associated with treatment failure and chemoradioresistance in oral squamous cell carcinoma
}

Tae Mi Yoon ${ }^{1}$, Sun-Ae Kim¹, Wan Seok Cho ${ }^{1}$, Dong Hoon Lee', Joon Kyoo Lee ${ }^{1}$, Young-Lan Park², Kyung-Hwa Lee ${ }^{3}$, Jae Hyuk Lee ${ }^{3}$, Sun-Seog Kweon', Ik-Joo Chung², Sang Chul Lim ${ }^{1}$ and Young-Eun Joo ${ }^{2 *}$

\begin{abstract}
Background: In humans, sex-determining region-Y (SRY) related high-mobility-group box 4 (SOX4) is linked to development and tumorigenesis. SOX4 is over-expressed in several cancers and has prognostic significance. This study evaluated whether SOX4 affects oncogenic behavior and chemoradiotherapy response in head and neck squamous cell carcinoma (HNSCC) cells, and documented the relationship between its expression and prognosis in oral squamous cell carcinoma (OSCC).

Methods: We used small interfering RNA in HNSCC cells to evaluate the effect of SOX4 on cell proliferation, apoptosis, chemoradiation-induced apoptosis, invasion, and migration. SOX4 expression in OSCC tissues was investigated by immunohistochemistry.
\end{abstract}

Results: SOX4 knockdown (KO) decreased cell proliferation and induced apoptosis by activating caspases-3 and -7, and poly-ADP ribose polymerase and suppressing X-linked inhibitor of apoptosis protein in HNSCC cells; it also enhanced radiation/cisplatin-induced apoptosis; and suppressed tumor cell invasion and migration. Immunostaining showed SOX4 protein was significantly increased in OSCC tissues compared with adjacent normal mucosa. SOX4 expression was observed in $51.8 \%$ of 85 OSCC tissues, and was significantly correlated with treatment failure $(P=0.032)$ and shorter overall survival $(P=0.036)$ in patients with OSCC.

Conclusions: SOX4 may contribute to oncogenic phenotypes of HNSCC cells by promoting cell survival and causing chemoradioresistance. It could be a potential prognostic marker for OSCC.

Keywords: SOX4 protein, Radioresistance, Apoptosis, Molecular targeted therapy, Oral cancer, Head and neck squamous cell carcinoma

\section{Background}

Oral cavity cancer accounts for approximately $28 \%$ of all head and neck cancers [1]. Squamous cell carcinomas represent about $90 \%$ of oral cavity cancer. Oral squamous cell carcinoma (OSCC) is the sixth most prevalent malignancy worldwide and the third most common cancer in developing nations [1]. Surgery, radiation therapy, chemotherapy or combinations of these modalities are standard options for managing OSCC; therapeutic

\footnotetext{
* Correspondence: yejoo@chonnam.ac.kr

${ }^{2}$ Departments of Internal Medicine, Chonnam National University Medical School and Hwasun Hospital, 8 Hak-Dong, Dong-Ku, Gwangju 501-757,

South Korea

Full list of author information is available at the end of the article
}

strategies are based on disease stage [2]. As advancedstage OSCC has a poor prognosis [1], understanding the molecular and biological changes of its progression is critical to development of more effective therapies.

In humans, the sex-determining region $\mathrm{Y}(\mathrm{SRY})$ related high-mobility-group (HMG) box family-also called the SOX family-includes 20 highly conserved transcription factors that affect diverse developmental processes [3]. SOX4 is essential to endocardial development and lymphocyte differentiation [3, 4]. Reportedly, SOX4 expression results in alterations of oncogenic phenotypes, including inhibition of apoptosis, cell-cycle progression and irradiation-induced apoptosis, and promotion of epithelial to mesenchymal transition in a variety of cancer 
cells [5-12]. SOX4 expression has also been reported to be highly expressed in various cancer tissues [5-14]. However, its role in tumor progression and clinical outcomes is unclear and has shown certain contradictions in different cancers. High SOX4 expression has been associated with better prognosis for patients with hepatocelluar carcinoma, medulloblastoma, and bladder cancer [5, 13, 14], but with shorter survival in prostate cancer, gastric cancer, and colon cancer $[7,9,10]$. Thus, SOX4 might exert different effects depending on tumor cell types and context.

Little is known about the molecular and prognostic significance of SOX4 in OSCC, although one report correlated SOX4 expression with OSCC tumor stage [12]. In the present study, we investigated whether SOX4 affects tumor cell behaviors such as cell proliferation, apoptosis, invasion, migration, and chemoradiation-induced apoptosis in head and neck squamous cell carcinoma (HNSCC) cells to validate its potential as a novel molecular target. We also assessed its prognostic value in OSCC.

\section{Methods}

Cell culture and transfection

The HNSCC cell lines (PCI 50 and SNU 1041) were kindly provided by Dr. Sung MW (Seoul National University, Seoul, South Korea). The normal immortalized human keratinocyte cell line $(\mathrm{HaCaT})$ was purchased from the American Type Culture Collection (Manassas, VA, USA). Cell lines were cultured in DMEM or RPMI1640 (Hyclone, Logan, UT, USA) supplemented with $10 \%$ fetal bovine serum (Hyclone) in a humidified atmosphere of $5 \% \mathrm{CO}_{2}$ at $37{ }^{\circ} \mathrm{C}$. For transfection, cells were seeded on 6 -well plates at $2 \times 10^{5}$ cells per well at the time of transfection. Small interfering RNA (siRNA) was used to knock down endogenous $\mathrm{SOX} 4$ gene expression in HNSCC cells. Cells were transfected with SOX4-specific siRNA (Bioneer, Daejeon, Korea) or negative control siRNA (Qiagen, Valencia, CA, USA) using Lipofectamine ${ }^{\mathrm{TM}} 2000$ (Invitrogen, Carlsbad, CA, USA) for 48 h. SOX4 knockdown (SOX4-KO) was checked by reverse transcriptionpolymerase chain reaction (RT-PCR) and western blotting.

\section{RNA isolation and RT-PCR}

The total RNA from cells was extracted using Trizol reagent (Invitrogen), reverse transcribed, and amplified using specific primers for SOX4 and glyceraldehyde 3phosphate dehydrogenase $(G A P D H)$, as previously described [15]. The extracted RNA loading was performed to verify the RNA integrity and double band (18S and 28S) was detected (Additional file 1). Primer sequences were: SOX4: 5' -GCA CAT GGC TGA CTA CCCC -3'/ 5'-GCC TTGTAC AGC GAG TGG TG-3'; and GAPDH: 5'-ACC ACA GTC CAT GCC ATC AC-3'/ 5'-TCC ACC ACC CTG TTG CTG TA-3'. PCR products were separated by electrophoresis on a $1 \%$ agarose gel containing ethidium bromide. The signals were quantified by densitometric analysis using the Labworks Image Acquistion (UVP, Upland, CA).

\section{Protein isolation and western blot analysis}

Cells were lysed in RIPA buffer. Resolved proteins were electrophoretically transferred to polyvinylidene fluoride membranes. Specific proteins were sequentially blotted with primary antibodies: SOX4 (Catalogue\# ab80261, Abcam, Cambridge, Mass, USA), cleaved caspase-3, cleaved caspase-7, cleaved poly-ADP ribose polymerase (PARP; Cell Signaling Technology, Danvers, MA, USA), X-linked inhibitor of apoptosis protein (XIAP) and polyclonal antiGAPDH (Santa Cruz Biotechnology, CA, USA). Each membrane was incubated with anti-rabbit or antimouse HRP-conjugated secondary antibody (Santa Cruz Biotechnology). Immunoreactive proteins were visualized on the enhanced chemiluminescence detection system HRP substrate (Millipore, Billerica, MA, USA). The immunoreactive bands were quantified by densitometric analysis using the luminescent image analyzer LAS-4000.

\section{Cell proliferation assay}

Cells were seeded in a 96-well plate $\left(5 \times 10^{3}\right.$ cells/well), and were transfected with SOX4 siRNA and negative control siRNA the next day. After incubation for $48 \mathrm{~h}$, cell proliferation and viability were measured using the EZ-CyTox (tetrazolium salts, WST-1) cell viability assay kit (Daeil Lab Inc, Seoul, South Korea). After adding WST-1 reagent for $1-2 \mathrm{~h}$ at $37{ }^{\circ} \mathrm{C}$, absorbance at $460 \mathrm{~nm}$ was determined using a microplate reader (Infinite M200; Tecan, Austria GmbH, Austria) with Magellan V6 data analysis software (Tecan). Triplicate wells were used for experimental conditions and all experiments were repeated at least three times.

\section{Apoptosis assay}

Apoptosis was determined by an Annexin V-fluorescein isothiocyanate (FITC) assay. Forty-eight hours after transfection, cells transfected with SOX4 siRNA or negative control siRNA were collected using trypsin, washed twice in phosphate buffered saline (PBS), and re-suspended in binding buffer (BD Biosciences, San Diego, CA, USA). Annexin V-FITC and 7-amino-actinomycin D (7-AAD; $\mathrm{BD}$ Biosciences) were added to the cells, which were incubated in the dark for $15 \mathrm{~min}$, then re-suspended in $400 \mathrm{ml}$ of binding buffer. Cells were analyzed using a FACSCalibur flow cytometer (Becton Dickinson, San Jose, CA). Data analysis was performed using standard Cell Quest software (Becton Dickinson).

\section{Cell irradiation and Cisplatin treatment}

Cells were treated with $\gamma$-irradiation at a single dose of 5 Gy $\left({ }^{137} \mathrm{Cs}, 2.875 \mathrm{~Gy} / \mathrm{min}\right)$ using a Gammacell irradiator 
(Gammacell, Otawa, Canada) [16, 17]. Cells were treated with cisplatin at $10 \mu \mathrm{g} / \mathrm{ml}$ (Pharmachemie BV, New York, USA) for $24 \mathrm{~h}$ at $37^{\circ} \mathrm{C}$.

\section{Cell invasion assay}

Cell invasion ability was measured by the number of cells that invaded through a transwell invasion apparatus with $8.0-\mu \mathrm{m}$ pores (Costar, Cambridge, UK). Living cells transfected with SOX4 siRNA or negative control siRNA were seeded at $3 \times 10^{5}$ cells in $120 \mu \mathrm{l}$ of a $0.2 \%$ bovine serum albumin (BSA) suspension in the upper chamber. We then loaded $400 \mu \mathrm{l}$ of $0.2 \%$ BSA containing $7-\mu \mathrm{g} / \mathrm{ml}$ fibronectin (Calbiochem, La Jolla, CA, USA) into the lower chamber as the chemoattractant. After incubation for $24 \mathrm{~h}$, cells that had moved to the bottom Transwell surface were stained with Diff Quik solution (Sysmex, Kobe, Japan) and calculated in five random squares in the microscopic field of view. Results are shown as mean \pm standard error of the number of cells/field in three individual experiments.

\section{Cell migration assay (wound healing assay)}

Cells transfected with SOX4 siRNA or negative control siRNA were seeded in each well of Culture-Inserts (Ibidi, Bonn, Germany) at $1.5 \times 10^{5}$ cells/well. After incubation for $24 \mathrm{~h}$, each insert was detached and the progression of cell migration was ascertained by photography at 0,4 , 8,12 , and $24 \mathrm{~h}$, using an inverted microscope. Distances between gaps were normalized to $1 \mathrm{~cm}$ after capture of three random sites.

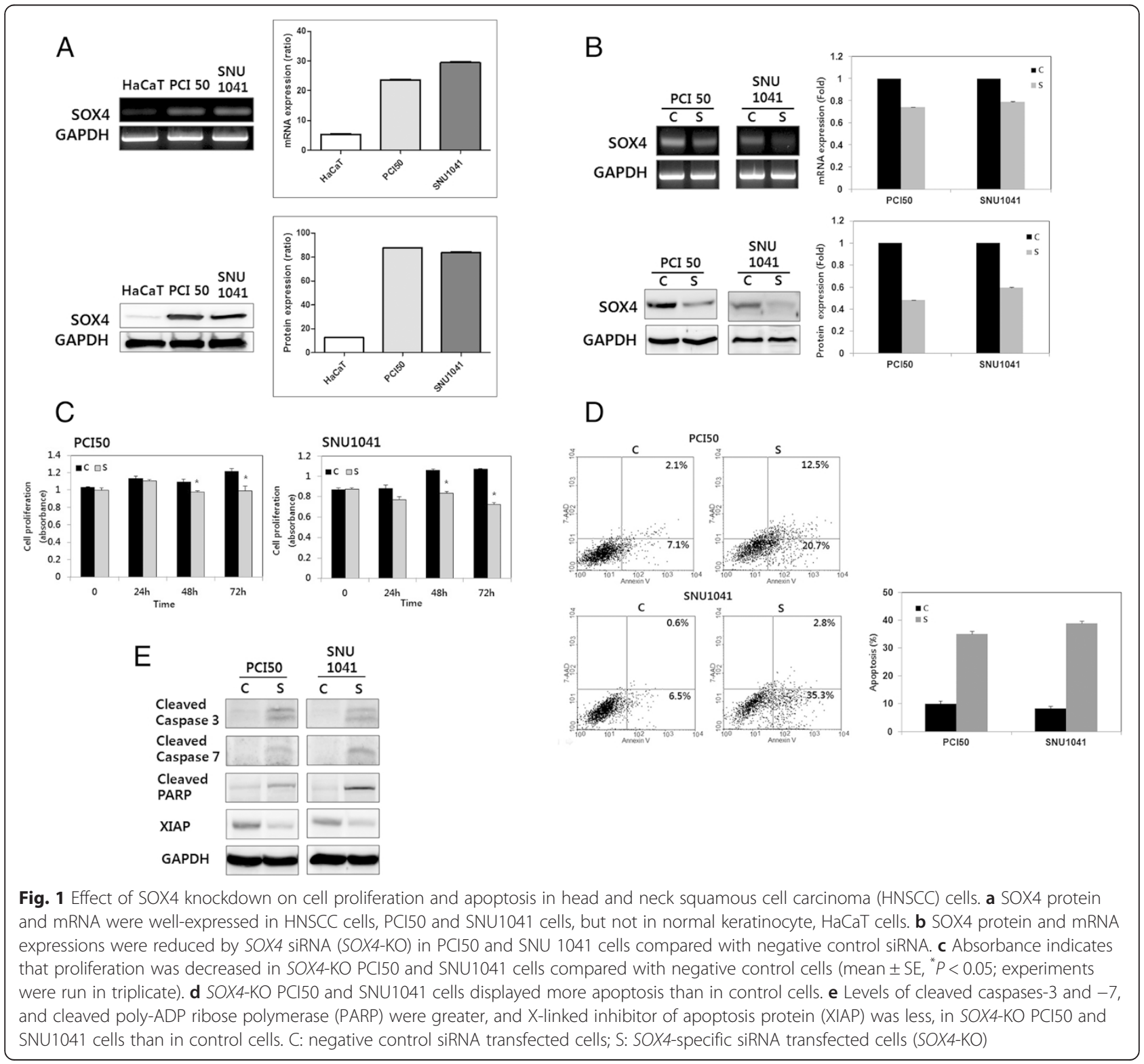




\section{Patients and tumor specimens}

To evaluate SOX4 protein expression, paraffin-embedded tissue sections were collected from 95 patients who had undergone diagnostic biopsy or definitive surgery for OSCC at Chonnam National University Hwasun Hospital (Jeonnam, Korea) between May 2004 and June 2013. None of the collected tissues were obtained after radiotherapy and/or chemotherapy. Ten patients were excluded, because of follow-up loss or palliative treatment intent. Of the 85 remaining patients, 82 patients were treated with definitive surgery with/without adjuvant radiotherapy or cisplatinbased concurrent chemoradiotherapy (CRT). Three patients, who refused surgery, were treated with induction chemotherapy, followed by cisplatin-based concurrent CRT with curative intent. Patients with locoregional recurrence after primary treatment underwent salvage surgery or CRT. Of 85 patients in our study, 50 (58.8 \%) underwent chemotherapy and/or radiotherapy. Treatment failure was defined as disease with inoperable locoregional progression or distant metastasis, even through salvage treatment. Patients provided the written informed consents for the surgical procedures, as well as for the use of resected tissue specimens. Patients' clinicopathologic characteristics were reviewed in hospital records. Tumors were staged according to the seventh edition of the American Joint Committee on Cancer staging system [18]. Survival was measured from the date of starting treatment to the date of death or date last seen. This study was approved by the Institutional Review Board of Chonnam National University Hwasun Hospital (CNUHH-2015-028).

\section{Immunohistochemistry}

Tissue processing and immunohistochemical analysis were performed as previously described [15]. The tissues were incubated with polyclonal rabbit anti-human SOX4 (Abcam). Immunohistochemsitry was performed in five batches, averaging 18 samples, with one positive and one negative control per batch. Negative controls were treated similarly, except that primary antibodies were omitted.

Two independent observers interpreted SOX4 staining of specimens with no knowledge of the clinical information. Intensity was scored as follows: 0, no staning of tumor cells; 1+, weak to comparable staining in cytoplasm and/or the nucleus compared to that of nontumoral cells; $2+$, readily appreciable or dark brown staining distinctly marking the tumor cell cytoplasm and/or nucleus [10]. Percentages of stained cells were scored as follows: 0: $0 \%$; 1: 1-25\%; 2: 26-50 \%; 3: 51$75 \%$; and $4,>75 \%[6,7]$. Final staining scores were the product of the intensity and percentage scores, with $\leq 4$ defined as low SOX4 expression and $>4$ defined as high SOX4 expression. Staining scores were discordant between the two pathologists (KHL and JHL) in five cases $(5 / 85, K=0.875)$, which were re-evaluated by the two pathologists, who then reached an agreement for each inconclusive sample.

\section{Statistical analyses}

Relationships between SOX4 expression and various clinicopathologic parameters were compared using the
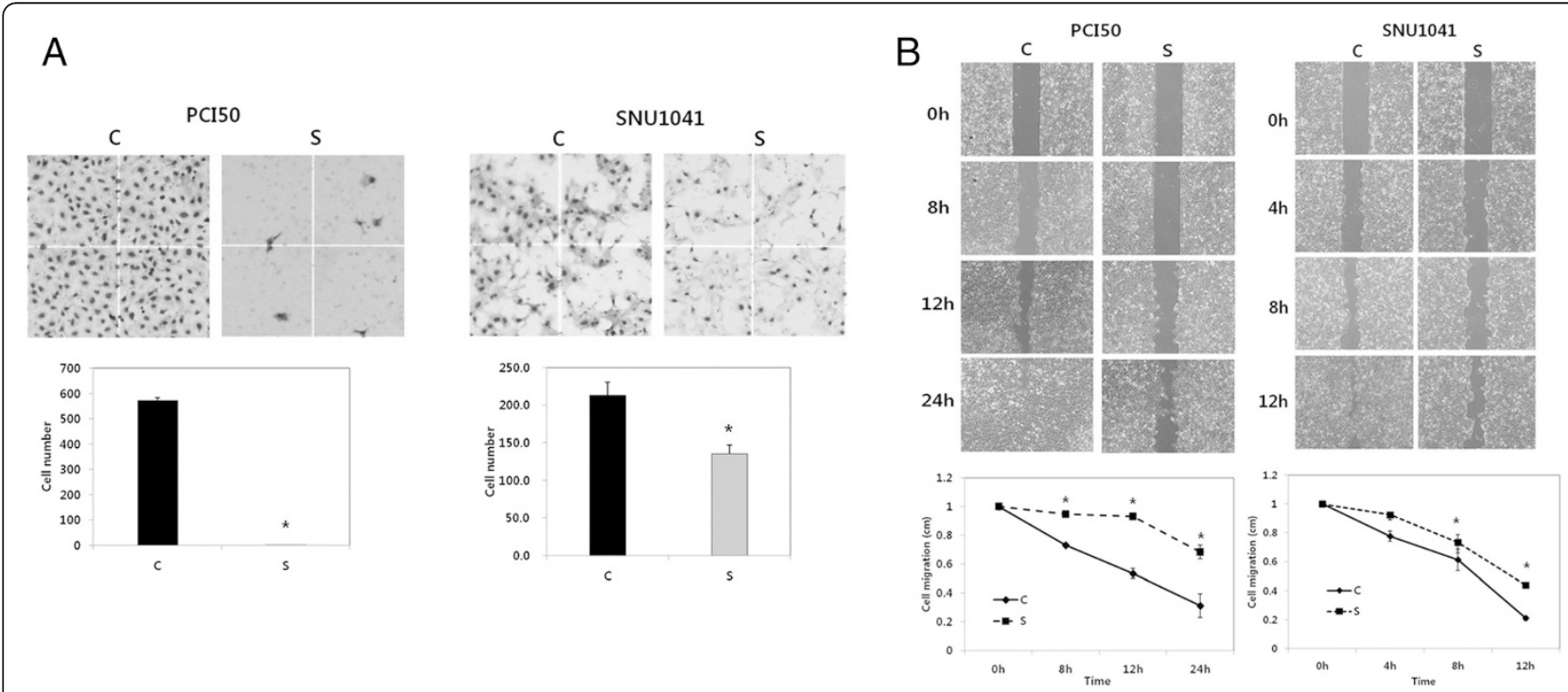

Fig. 2 Effects of SOX4 knockdown (SOX4-KO) on cell invasion and migration in head and neck squamous cell carcinoma cells. a In the cell invasion assay, significantly fewer SOX4-KO PCI50 and SNU1041 cells invaded than did negative control cells. Stained invading cells were counted (bar graph; mean $\pm \mathrm{SE}$, experiments were run in triplicate; ${ }^{*} P<0.05$ ). $\mathbf{b}$ Cell migration was significantly less in SOX4-KO PCI50 and SNU1041 cells than in negative control cells (displayed as relative healing distances measured in three random sites). Values indicate mean \pm SE for three independent experiments ( $P<0.05)$. C: negative control siRNA transfected cells; S: SOX4-specific siRNA transfected cells (SOX4-KO) 
A

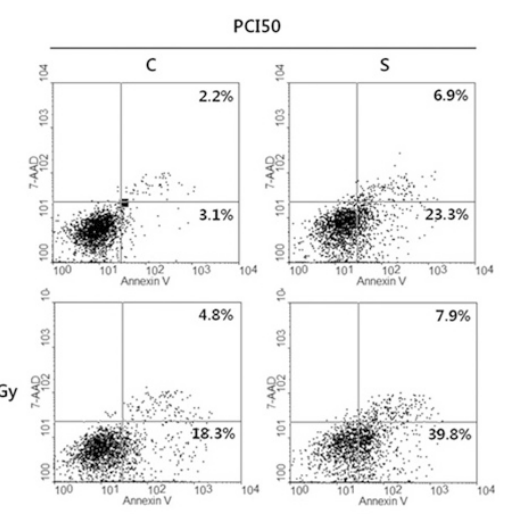

B
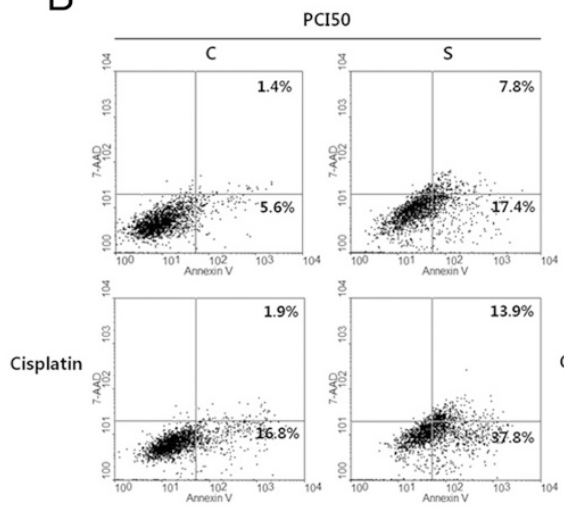

C
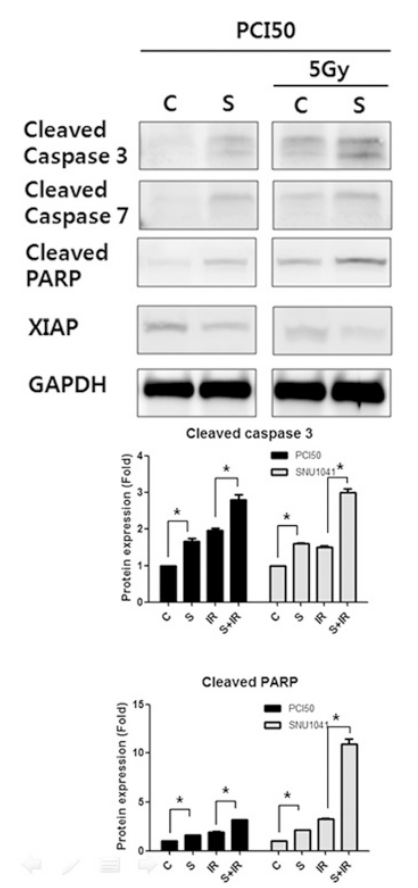
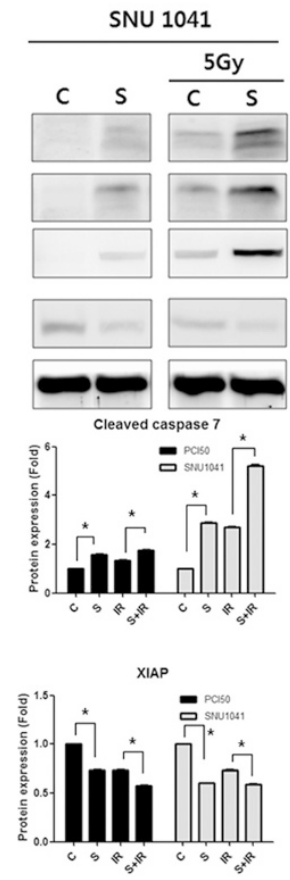
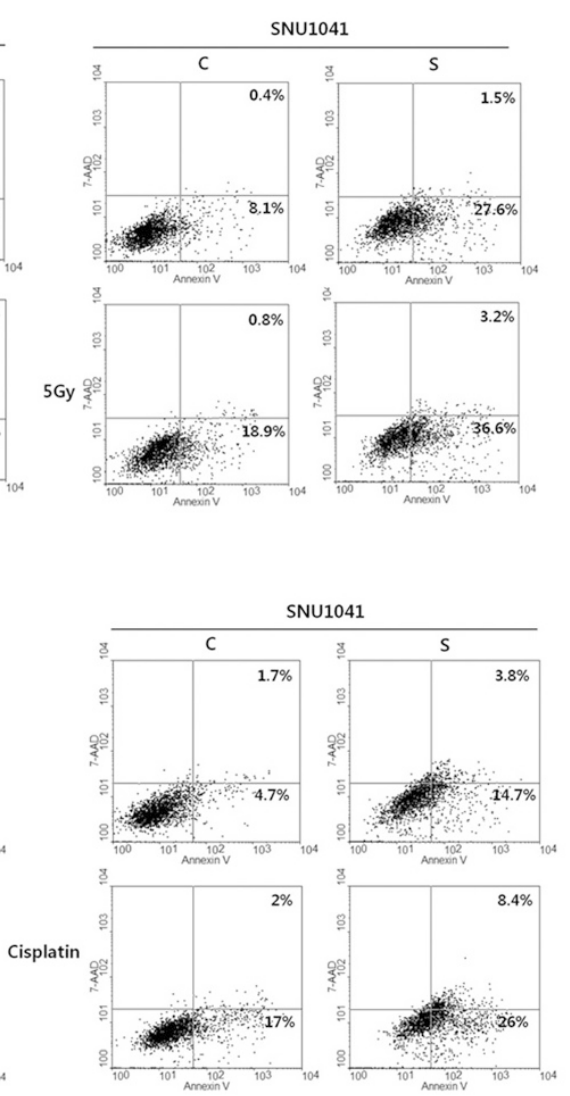

D

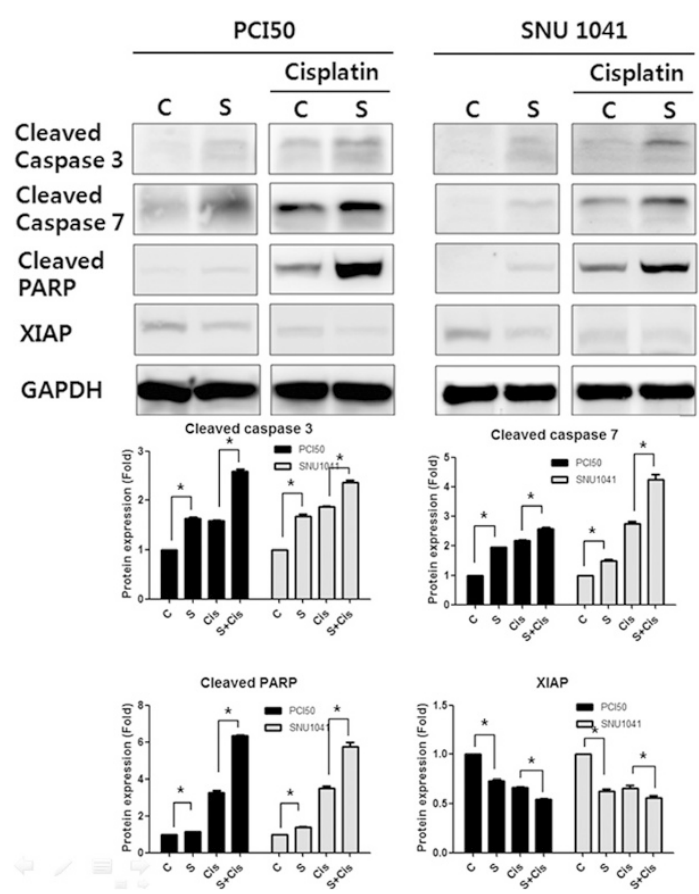

Fig. 3 (See legend on next page.) 
(See figure on previous page.)

Fig. 3 Effects of SOX4 knockdown (SOX4-KO) on radiosensitivity and cisplatin chemosensitivity in head and neck squamous cell carcinoma cells. a, b Combination treatment of SOX4-KO with 5 Gy radiation or cisplatin resulted in significantly more apoptosis in PCI50 and SNU1041 cells than in control cells treated with 5 Gy radiation or cisplatin treatment alone. c, d SOX4-KO cells showed greater expression of cleaved caspases-3 and -7 , and cleaved poly-ADP ribose polymerase (PARP), and less X-linked inhibitor of apoptosis protein (XIAP), than did control cells after 5 Gy radiation or cisplatin treatment $\left({ }^{*} P<0.05\right)$. C: negative control siRNA transfected cells; S: SOX4-specific siRNA transfected cells $(S O X 4-K O)$; Cis: cisplatin treatment; IR: irradiation

$X^{2}$ test and Fisher's exact test. Survival curves were calculated by the Kaplan-Meier method, and compared using the log-rank test. Experimental differences between the SOX4-KO group and control group were tested with the Mann-Whitney $U$ test. Analyses used Statistical Package for the Social Sciences (SPSS) version

Table 1 Association between SOX4 expression and clinicopathological parameters in patients with oral squamous cell carcinoma

\begin{tabular}{|c|c|c|c|c|}
\hline \multirow[t]{2}{*}{ Parameters } & \multirow[b]{2}{*}{ Total $(n=85)$} & \multicolumn{2}{|c|}{ SOX4 expression } & \multirow[t]{2}{*}{$p$-value } \\
\hline & & Low $(n=41)$ & High $(n=44)$ & \\
\hline Age (yr) & & & & 0.161 \\
\hline$<64$ & 41 & 23 & 18 & \\
\hline$\geq 64$ & 44 & 18 & 26 & \\
\hline Sex & & & & 0.492 \\
\hline Male & 61 & 28 & 33 & \\
\hline Female & 24 & 13 & 11 & \\
\hline Location & & & & 0.654 \\
\hline Oral tongue & 60 & 28 & 32 & \\
\hline FOM, BM, RMT & 25 & 13 & 12 & \\
\hline Stage & & & & 0.651 \\
\hline I, II & 56 & 28 & 28 & \\
\hline III, IV & 29 & 13 & 16 & \\
\hline T stage & & & & 0.843 \\
\hline $\mathrm{T} 1, \mathrm{~T} 2$ & 74 & 36 & 38 & \\
\hline $\mathrm{T} 3, \mathrm{~T} 4$ & 11 & 5 & 6 & \\
\hline$N$ stage & & & & 0.327 \\
\hline No & 60 & 31 & 29 & \\
\hline $\mathrm{N} 1, \mathrm{~N} 2$ & 25 & 10 & 15 & \\
\hline CRT & & & & 0.622 \\
\hline No & 35 & 23 & 27 & \\
\hline Yes & 50 & 18 & 17 & \\
\hline Recurrence & & & & 0.004 \\
\hline No & 53 & 32 & 21 & \\
\hline Yes & 32 & 9 & 23 & \\
\hline Treatment failure & & & & 0.032 \\
\hline No & 59 & 33 & 26 & \\
\hline Yes & 26 & 8 & 18 & \\
\hline
\end{tabular}

FOM = floor of mouth; $\mathrm{BM}=$ buccal mucosa; RMT = retromolar trigone; $\mathrm{CRT}=$ chemotherapy and/or radiotherapy; $X^{2}$ test and Fisher's exact test was used
21.0 (Microcal Software Inc, Chicago, IL, USA). $P<0.05$ was considered significant.

\section{Results}

SOX4-KO suppresses tumorigenic activities in HNSCC cells Initially, SOX4 expression at mRNA and protein levels was evaluated in HNSCC cells and HaCaT cells. Western blot and RT-PCR showed SOX4 to be well-expressed in PCI50 and SNU1041 cells, but negligibly expressed in $\mathrm{HaCaT}$ cells relative to HNSCC cells (Fig. 1a). To explore the role of SOX4 on oncogenic activities and treatment response in HNSCC cells, we used siRNA to inhibit endogenous SOX4 expression in HNSCC cell lines including PCI50 and SNU1041 cells. SOX4 mRNA and protein expressions were reduced by SOX4 siRNA in PCI50 and SNU 1041 cells compared with cells treated with negative control siRNA (Fig. 1b).

\section{SOX4-KO decreases cell proliferation in HNSCC cells}

Proliferating cells, as determined by absorbance, were significantly decreased in SOX4-KO cells at $48 \mathrm{~h}$ and $72 \mathrm{~h}$ in PCI50 and SNU1041 cells, as compared with negative control cells $(P=0.002$; Fig. 1 c) .

\section{SOX4-KO enhances apoptosis in HNSCC cells}

To evaulate the effect of SOX4 on apoptosis, we used an Annexin V apoptosis assay. SOX4-KO PCI50 and SNU1041 cells displayed greater apoptotic rates than did control cells (Fig. 1d). The proportion of early and late apoptotic cells induced by transfection of SOX4 siRNA was greater than that induced by transfection of negative control siRNA $(9.2 \%$ vs. $33.2 \%$ and $7.1 \%$ vs. $38.1 \%$, respectively) in PCI50 and SNU1041 cells. Next, we investigated apoptosis regulatory proteins after SOX4-KO treatment. Levels of cleaved caspases- 3 and -7 , and PARP were increased, and the level of XIAP was decreased, in SOX4-KO PCI50 and SNU1041 cells, compared with negative control cells (Fig. 1e). These results suggest that SOX4-KO-induced apoptosis is associated with the modulation of apoptosis regulatory proteins such as caspases-3 and -7, PARP and XIAP.

\section{SOX4-KO suppresses the tumor cell invasion and migration in HNSCC cells}

In the cell invasion assay, the invasiveness of SOX4-KO PCI50 cells and SNU1041 cells was significantly decreased 
compared with that of negative control cells $(P<0.05$; Fig. 2a). In the cell migration assay, the migratory ability of SOX4-KO cells was significantly less than that of negative control cells at $8 \mathrm{~h}, 12 \mathrm{~h}$, and $24 \mathrm{~h}$ in PCI50 cells, and $8 \mathrm{~h}$ and $12 \mathrm{~h}$ in SNU1041 cells $(P<0.05$; Fig. $2 \mathrm{~b})$.

\section{SOX4-KO enhances radiosensitivity and cisplatin chemosensitivity in HNSCC cells}

We addressed whether SOX4-KO enhances cisplatin chemosensitivity and radiosensitivity by the induction of apoptosis in PCI50 and SNU1041 cells. Twenty-four hours after transfection with SOX4 siRNA or negative control siRNA, cells were treated with 5 Gy radiation or cisplatin $(10 \mu \mathrm{g} / \mathrm{ml}$ for $24 \mathrm{~h}$ ). The combination of SOX4 siRNA and radiation resulted in significantly greater apoptosis compared with radiation alone (Fig. 3a). The percentages of early and late apoptotic cells induced by SOX4 siRNA + 5 Gy radiation were greater than those seen in negative control cells treated with 5 Gy radiation ( $23.1 \%$ vs. $47.7 \%$ and $19.7 \%$ vs. 39.8 \%, respectively) in PCI50 and SNU1041 cells. Similarly, the combination of SOX4 siRNA + cisplatin resulted in markedly greater apoptosis compared with cells treated with cisplatin alone (Fig. 3b), with larger percentages of early and late apoptotic cells in the SOX4 siRNA + cisplatin-treated cells than in the negative control treated with cisplatin only (18.7\% vs. $51.7 \%$ and $19.0 \%$ vs. $34.4 \%$, respectively) in PCI50 and SNU1041 cells. Consistently, the SOX4-KO cells showed greater expression of cleaved caspases- 3 and -7 and PARP, and less XIAP, after radiation or cisplatin treatment compared with the control cells (Fig. 3c, d). These findings suggest that the combination of SOX4-KO and CRT has synergistic apoptotic effects in HNSCC cells.

\section{SOX4 expression is associated with treatment failure and survival in OSCC}

\section{SOX4 expression in OSCC tissues}

The clinicopathological characteristics of the 85 OSCC patients in this study group are summarized in Table 1. The patients included 61 men and 24 women, whose mean age was $63.2 \pm 12.5$ years ( \pm standard deviation), with a range of $26-87$ years. Their mean follow-up period was $43.7 \pm 27.7$ months (range: $3.6-125.3$ months). SOX 4 protein expression was investigated immunohistochemically in formalin-fixed, paraffin-embedded blocks of specimens from these 85 patients. Immunostaining patterns were heterogenous, with predominantly nuclear and/or cytoplasmic immunostained SOX4 protein in tumor cells, but with weak or no staining in the normal oral mucosa (Fig. 4). Based on our criteria [6, 7, 10], 44 (51.8 \%) of the 85 OSCC specimens showed high SOX4 expression.

\section{Correlation between SOX4 expression and clinicopathologic factors in OSCC tissues}

To study the prognostic role of SOX4 in OSCC, we investigated the correlation between SOX4 expression and clinicopathological factors. SOX4 expression in OSCC was not associated with age, sex, location, $T$ stage (tumor invasion), $\mathrm{N}$ stage or lymph node metastasis $(P>0.05$, Table 1$)$. However, SOX4 expression was correlated with recurrence $(P=0.004)$ and treatment failure $(P=0.032$; Table 1$)$. Moreover, overall survival (OS) and diease specific survival (DSS) of patients with high SOX4 expression was significantly shorter than for those with low SOX4 expression ( $P=0.036$ and $P=0.007$, respectively; Fig. 5a). In 50 patients who were treated with chemotherapy

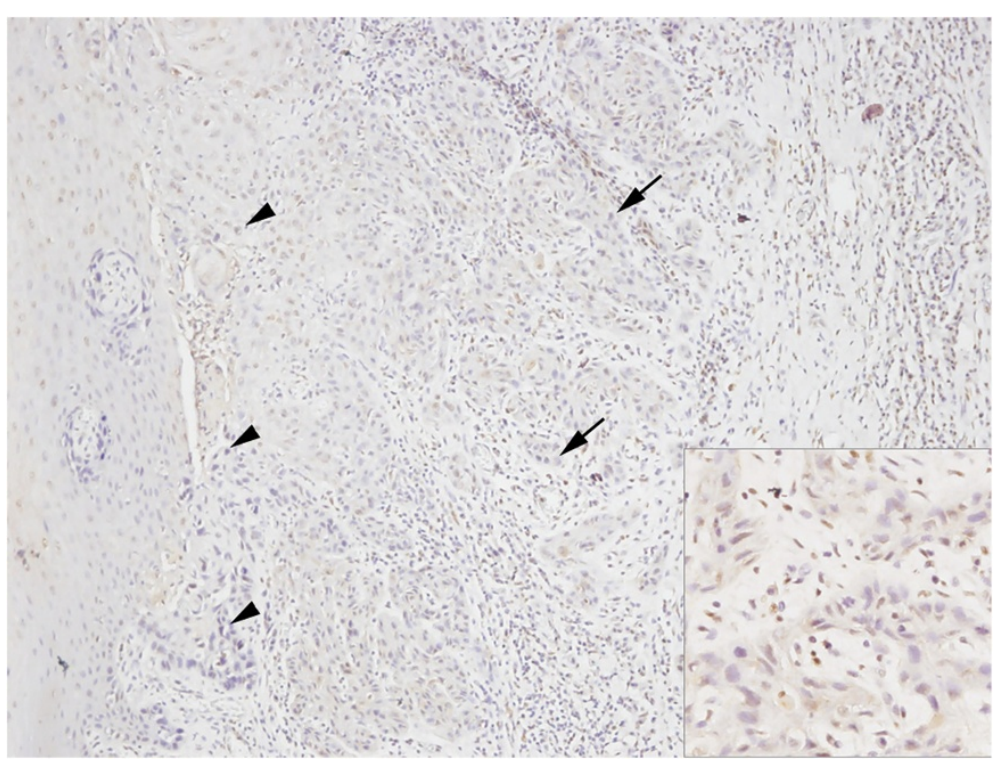

Fig. 4 Expression of SOX4 protein in oral squamous cell carcinoma (OSCC) specimens. Immunostaining showed SOX4 protein was significantly increased in OSCC tissues (arrow) compared with adjacent normal mucosa (arrow head). ( $\times 100, \times 200$ in the inlet box) 


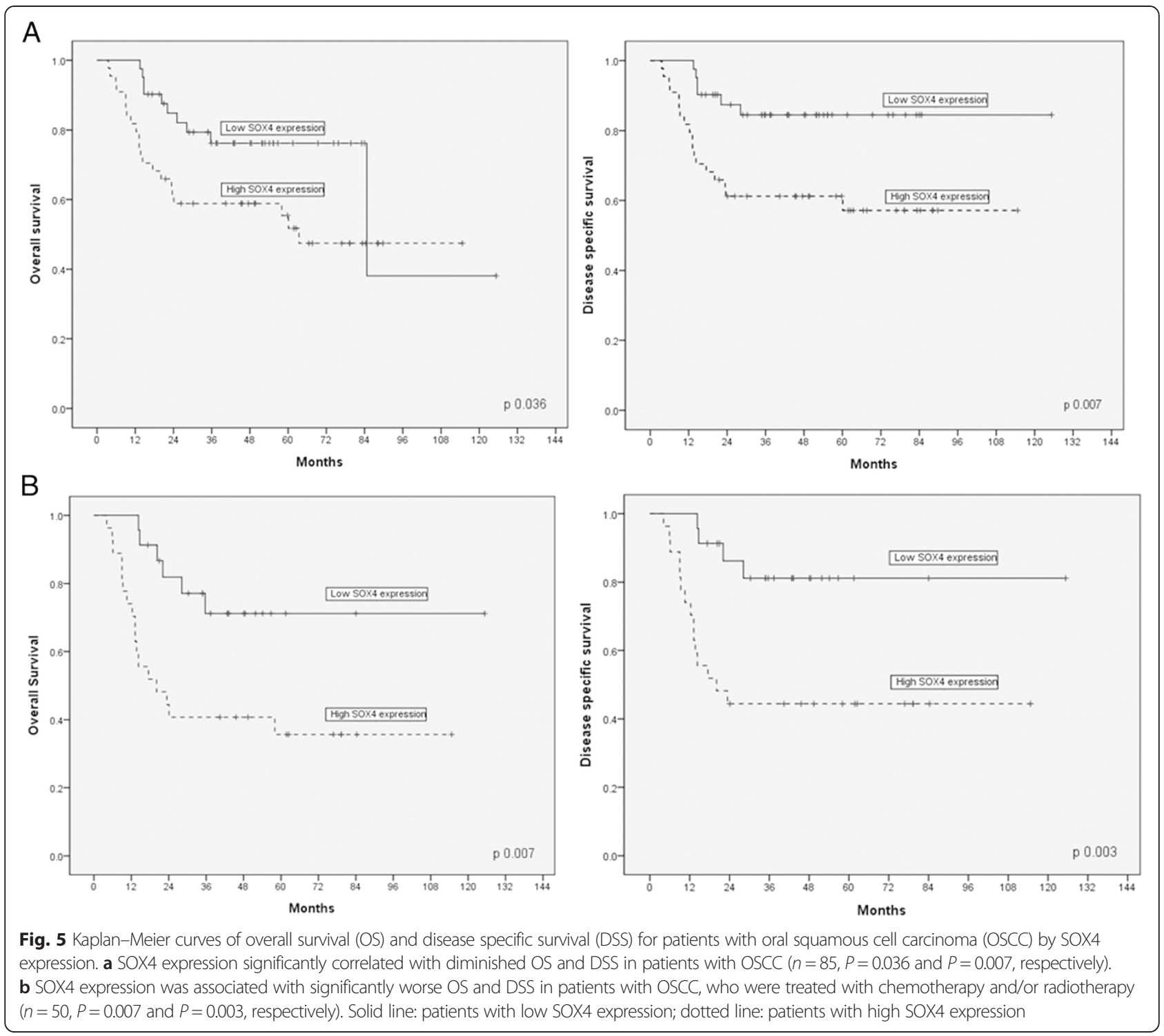

and/or radiotherapy, patients with high SOX4 expression had significantly shorter OS and DSS than those with low SOX4 expression $(P=0.007$ and $P=0.003$, respectively; Fig. 5b).

\section{Discussion}

Initiation and progression of cancer are caused by alterations in transcriptional activities, resulting in an imbalance between oncogenes and tumor suppressor genes [19]. Transcription factors are deregulated in their expression and function during tumorigenesis [19]. The SOX transcription factor family plays a key role in many developmental processes by controlling terminal differentiation of a wide variety of cell types and cell fate decisions [20]. Consequently, deregulation of several SOX genes have been implicated in tumorigenesis [20]. SOX4 belongs to the $\mathrm{C}$ subgroup of the SOX family. High
SOX4 expression has been shown to affect tumor development or progression in gastric cancer, colon cancer, prostate cancer, breast cancer, lung cancer, and endometrial cancer [7-10, 21, 22]. The mechanism by which SOX4 is involved in tumor development and progression in many cancers remains unclear.

Tumorigenesis results from an imbalance between cell proliferation and cell death; most of the latter occurs through apoptosis [23]. Therefore, the primary mechanism through which SOX4 affects tumor initiation and progression may be deregulation of apoptosis. SOX4 gene encodes a protein with three distinguishable domains: an HMG box, a serine-rich region, and a glycinerich central domain [24]. The HMG box binds DNA, whereas the central domain is a functional region for regulating apoptotic cell death [24]. Therefore, we evaluated the impact of SOX4 in cell proliferation and 
apoptosis in HNSCC cells. In this study, knocked-down SOX4 induced apoptosis and suppressed cell proliferation, which indicates that SOX4 supresses apoptosis in HNSCC cells. Additionally, SOX4-KO-induced apoptosis was associated with the modulation of apoptosis-related proteins such as caspases- 3 and -7 , PARP, and XIAP. Our results concord with reports in which SOX4-KO in adenoid cystic carcinoma and prostate cancer cells induced apoptosis $[6,7,25]$. Therefore, SOX4 exerts its anti-apoptotic function by directly inhibiting caspase activities and up-regulation of anti-apoptotic proteins, thus contributing to tumorigenesis in HNSCC.

Second, the anti-apoptotic function of SOX4 apparently causes resistance to anti-cancer treatement such as CRT. Cancer cells are often characterized by increased resistance to apoptosis [26]. Overcoming apoptotic resistance is important to improve response to tumor treatments, especially CRT. In the present study, knocked-down SOX4 enhanced radiation- or cisplatin-induced apoptosis in HNSCC cells, which were further supported by elevated levels of cleaved caspases-3 and -7, and PARP in SOX4KO HNSCC cells after radiation or cisplatin treatment. These results suggest that SOX4 inhibits radiation- or cisplatin- induced apoptosis, and contributes to CRT resistance in HNSCC cells. These findings are very important because CRT is used as primary or adjuvant treatment for locally advanced HNSCC (including OSCC), and CRT response is accepted as an important prognostic factor $[2,27]$. Our findings suggest that SOX4 can serve as a specific predictor for CRT response in HNSCC. Furthermore, a therapy in which SOX4 is targeted in combination with CRT might overcome apoptotic resistance and improve response in HNSCC.

Third, SOX4 appears to aggravate cell invasiveness and migration. HNSCC subtypes, including OSCC, are characterized by a marked propensity for local invasion and lymphatic metastasis. Understanding the molecular mechanisms that mediate tumor invasion and metastasis may enable identification of novel therapeutic targets for management of tumor dissemination. Our study showed that knocked-down SOX4 suppressed tumor cell invasion and migration in HNSCC cells; earlier studies showed it to significantly inhibit invasiveness and migration in prostate cancer cells [7]. These results indicate that SOX4 contributes to tumor progression and metastasis, and imply that SOX4 could be a useful target in cancer therapy.

Finally, SOX4 may serve as a biomarker for poor treatment response and outcome in OSCC. In this study, we found that SOX4 expression was significantly associated with recurrence, treatment failure and shorter OS. These results support our results of in vitro study, which associated SOX4 expression with oncogenic HNSCC phenotypes. Although several studies have associated SOX4 expression with shorter survival in prostate cancer, gastric cancer, and colon cancer $[7,9,10]$, this is the first to demonstrate the correlation between SOX4 expression and treatment failure in OSCC. More accurate prediction of treatment failure would facilitate earlier recurrence detection and maximize the therapeutic effects of salvage treatment. In particular, among patients with OSCC who received chemotherapy and/or radiotherapy, those with high SOX4 expression had significantly shorter OS. These findings indicate that SOX4-related chemoradioresistance has a pessimistic effect on survival in patients with OSCC.

\section{Conclusions}

Taken together, SOX4 may contribute to invasive and oncogenic phenotypes of HNSCC cells by promoting cell survival and causing chemoradioresistance. SOX4 may be a prognostic marker for OSCC survival outcomes and treatment response.

\section{Additional file}

Additional file 1: The extracted RNA loading was performed to verify the RNA integrity and double band ( $18 \mathrm{~S}$ and $28 \mathrm{~S})$ was detected. (JPEG $27 \mathrm{~kb}$ )

\section{Abbreviations}

BSA: Bovine serum albumin; CRT: Chemoradiotherapy; DSS: Diease specific survival; GAPDH: Glyceraldehyde 3-phosphate dehydrogenase; HMG: Highmobility-group; HNSCC: Head and neck squamous cell carcinoma; OS: Overall survival; OSCC: Oral squamous cell carcinoma; PARP: Poly-ADP ribose polymerase; PBS: Phosphate buffered saline; RT-PCR: Reverse transcription-polymerase chain reaction; siRNA: Small interfering RNA; SOX: Sex-determining region Y related high-mobility-group box; SOX4-KO: SOX4 knockdown; SPSS: Statistical Package for the Social Sciences; SRY: Sex-determining region Y; XIAP: X-linked inhibitor of apoptosis protein.

\section{Competing interests}

The authors declare that they have no competing interests.

\section{Authors' contributions}

TMY \& YEJ analyzed the data and drafted manuscript. SAK \& YLP performed the experimental study. WSC collected the clinical data. KHL, JHL, \& YEJ analyzed the pathological data. TMY \& SAK participated in the design of the study. TMY \& SSK performed the statistical analysis. DHL, JKL, IJC \& SCL helped the interpretation of data. YEJ conceived of the study. All authors read and approved the final manuscript.

\section{Acknowledgment}

This study was supported by a grant (HCRI 14028-22) Chonnam National University Hwasun Hospital Institute for Biomedical Science. We thank Dr. Sung MW (Seoul National University) for the PCI50 and SNU1041 cell lines.

\section{Author details}

${ }^{1}$ Departments of Otorhinolaryngology-Head and Neck Surgery, Chonnam National University Medical School and Hwasun Hospital, 8 Hak-Dong, Dong-Ku, Gwangju 501-757, South Korea. 'Departments of Internal Medicine, Chonnam National University Medical School and Hwasun Hospital, 8 Hak-Dong, Dong-Ku, Gwangju 501-757, South Korea. ${ }^{3}$ Departments of Pathology, Chonnam National University Medical School and Hwasun Hospital, 8 Hak-Dong, Dong-Ku, Gwangju 501-757, South Korea.

${ }^{4}$ Departments of Preventive Medicine, Chonnam National University Medical School and Hwasun Hospital, 8 Hak-Dong, Dong-Ku, Gwangju 501-757, South Korea. 
Received: 23 April 2015 Accepted: 30 October 2015

Published online: 10 November 2015

\section{References}

1. Siegel R, Naishadham D, Jemal A. Cancer statistics, 2013. CA Cancer J Clin. 2013;63:11-30

2. De Felice F, Musio D, Terenzi V, Valentini V, Cassoni A, Tombolini M, et al. Treatment improvement and better patient care: which is the most important one in oral cavity cancer? Radiat Oncol. 2014;9:263.

3. Schepers GE, Teasdale RD, Koopman P. Twenty pairs of sox: extent, homology, and nomenclature of the mouse and human sox transcription factor gene families. Dev Cell. 2002;3:167-70.

4. Schilham MW, Oosterwegel MA, Moerer P, Ya J, de Boer PA, van de Wetering $M$, et al. Defects in cardiac outflow tract formation and pro-B-lymphocyte expansion in mice lacking Sox-4. Nature. 1996;380:711-4.

5. Hur W, Rhim H, Jung CK, Kim JD, Bae SH, Jang JW, et al. SOX4 overexpression regulates the p53-mediated apoptosis in hepatocellular carcinoma: clinical implication and functional analysis in vitro. Carcinogenesis. 2010;31:1298-307.

6. Pramoonjago P, Baras AS, Moskaluk CA. Knockdown of Sox4 expression by RNAi induces apoptosis in ACC3 cells. Oncogene. 2006;25:5626-39.

7. Wang L, Zhang J, Yang X, Chang YW, Qi M, Zhou Z, et al. SOX4 is associated with poor prognosis in prostate cancer and promotes epithelial-mesenchymal transition in vitro. Prostate Cancer Prostatic Dis. 2013;16:301-7.

8. Z Zhang J, Liang Q, Lei Y, Yao M, Li L, Gao X, et al. SOX4 induces epithelial-mesenchymal transition and contributes to breast cancer progression. Cancer Res. 2012;72:4597-608.

9. Lin CM, Fang CL, Hseu YC, Chen CL, Wang JW, Hsu SL, et al. Clinical and prognostic implications of transcription factor SOX4 in patients with colon cancer. PLoS One. 2013;8:e67128.

10. Fang CL, Hseu YC, Lin YF, Hung ST, Tai C, Uen YH, et al. Clinical and prognostic association of transcription factor SOX4 in gastric cancer. PLoS One. 2012;7:e52804.

11. Coskunpinar E, Oltulu YM, Orhan KS, Tiryakioglu NO, Kanliada D, Akbas F. Identification of a differential expression signature associated with tumorigenesis and metastasis of laryngeal carcinoma. Gene. 2014;534:183-8.

12. Watanabe M, Ohnishi Y, Wato M, Tanaka A, Kakudo K. SOX4 expression is closely associated with differentiation and lymph node metastasis in oral squamous cell carcinoma. Med Mol Morphol. 2014:47:150-5.

13. de Bont JM, Kros JM, Passier MM, Reddingius RE, Sillevis Smitt PA, Luider TM, et al. Differential expression and prognostic significance of SOX genes in pediatric medulloblastoma and ependymoma identified by microarray analysis. Neuro Oncol. 2008;10:648-60.

14. Aaboe M, Birkenkamp-Demtroder K, Wiuf C, Sørensen FB, Thykjaer T, Sauter $\mathrm{G}$, et al. SOX4 expression in bladder carcinoma: clinical aspects and in vitro functional characterization. Cancer Res. 2006;66:3434-42.

15. Yoon TM, Kim SA, Park YL, Lee KH, Sung MW, Lee JK, et al. Expression of the receptor tyrosine kinase recepteur d'origine nantais and its association with tumor progression in hypopharyngeal cancer. Head Neck. 2013;35:1106-13.

16. Vellanki SH, Grabrucker A, Liebau S, Proepper C, Eramo A, Braun V, et al. Small-molecule XIAP inhibitors enhance gamma-irradiation-induced apoptosis in glioblastoma. Neoplasia. 2009;11:743-52.

17. Hennel R, Brix N, Seidl K, Ernst A, Scheithauer H, Belka C, et al. Release of monocyte migration signals by breast cancer cell lines after ablative and fractionated $\gamma$-irradiation. Radiat Oncol. 2014;9:85.

18. Edge SB, Byrd DR, Compton CC, Fritz AG, Greene FL, Tritti A. American joint committee on cancer-cancer staging manual. 7th ed. New York: Springer;2010.

19. Vervoort SJ, van Boxtel R, Coffer PJ. The role of SRY-related HMG box transcription factor 4 (SOX4) in tumorigenesis and metastasis: friend or foe? Oncogene. 2013;32:3397-409.

20. Harley V, Lefebvre V. Twenty Sox, twenty years. Int J Biochem Cell Biol. 2010:42:376-7.

21. Medina PP, Castillo SD, Blanco S, Sanz-Garcia M, Largo C, Alvarez S, et al. The SRY-HMG box gene, SOX4, is a target of gene amplification at chromosome 6p in lung cancer. Hum Mol Genet. 2009;18:1343-52.

22. Huang YW, Liu JC, Deatherage DE, Luo J, Mutch DG, Goodfellow PJ, et al. Epigenetic repression of microRNA-129-2 leads to overexpression of SOX4 oncogene in endometrial cancer. Cancer Res. 2009;69:9038-46.

23. Thompson CB. Apoptosis in the pathogenesis and treatment of disease. Science. 1995;267:1456-62.
24. Hur EH, Hur W, Choi JY, Kim IK, Kim HY, Yoon SK, et al. Functional identification of the pro-apoptotic effector domain in human Sox4. Biochem Biophys Res Commun. 2004;325:59-67.

25. Liu P, Ramachandran S, Ali Seyed M, Scharer CD, Laycock N, Dalton WB, et al. Sex-determining region $Y$ box 4 is a transforming oncogene in human prostate cancer cells. Cancer Res. 2006;66:4011-9.

26. Igney $\mathrm{FH}$, Krammer PH. Death and anti-death: tumour resistance to apoptosis. Nat Rev Cancer. 2002;2:277-88.

27. Lin HY, Hung SK, Lee MS, Chiou WY, Huang TT, Tseng CE, et al. DNA methylome analysis identifies epigenetic silencing of FHIT as a determining factor for radiosensitivity in oral cancer: an outcome-predicting and treatment-implicating study. Oncotarget. 2015;6:915-34.

\section{Submit your next manuscript to BioMed Central and take full advantage of:}

- Convenient online submission

- Thorough peer review

- No space constraints or color figure charges

- Immediate publication on acceptance

- Inclusion in PubMed, CAS, Scopus and Google Scholar

- Research which is freely available for redistribution

Submit your manuscript at www.biomedcentral.com/submit
C Biomed Central 